\title{
Land Disposal Restrictions (LDR) Program Overview
}

April 1993

\section{MASTER}

Prepared for the

U.S. Department of Energy

Office of Environmental Guidance Washington, D.C.

\section{Prepared by}

Martin Marietta Energy Systems, Inc. under contract No. DE-AC05-900R21851 


\section{Preface}

This document was prepared by the Office of Environmental Guidance, RCRA/CERCLA Division (EH-231) with the support of the Environmental Compliance Group, Environmental Sciences Division, Oak Ridge National Laboratory. Questions regarding the subject matter in this document should be directed to Ms. Beverly Whitehead, 1000 Independence Ave., S.W., Washington, D.C. 20585, at (202) 586-6073. 


\section{Land Disposal Restrictions (LDR) Program Overview}

\section{Background}

The Hazardous and Solid Waste Amendments (HSWA) tc the Resource Conservation and Recovery Act (RCRA) enacted in 1984 required the Environmental Protection Agency (EPA) to evaluate all listed and characteristic hazardous wastes according to a strict schedule and to develop requirements by which disposal of these wastes would be protective of human health and the environment. The implementing regulations for accomplishing this statutory requirement are established within the Land Disposal Restrictions (LDR) program. The LDR regulations (40 CFR Part 268) impose significant requirements on waste management operations and environmental restoration activities at DOE sites. For hazardous wastes restricted by statute from land disposal, EPA is required to set levels or methods of treatment that substantially reduce the waste's toxicity or the likelihood that the waste's hazardous constituents will migrate. Upon the specified LDR effective dates, restricted wastes that do not meet treatment standards are prohibited from land disposal unless they qualify for certain variances or exemptions. This document provides an overview of the LDR Program.

The HSWA established a series of statutory deadlines for EPA to implement rules defining conditions under which land disposal could occur. All of these deadiines established by statute have passed. These statutory deadlines apply to particular groupings of wastes that were listed or identified as hazardous as of November 8, 1984. Pursuant to HSWA, hazardous wastes listed or identified after 1984 must be addressed within six months of the date of identification or listing. EPA has not 
met this requirement for establishing standards for all newly listed or identified wastes.

\section{Applicability}

In the regulations that implement the LDR requirements, land disposal means placement in or on the land and includes, but is not limited to placement in a landfill, surface impoundment, waste pile, injection well, land treatment facility, salt dome formation, salt bed formation, underground mine or cave, or placement in a concrete vault or bunker intended for disposal purposes (40 CFR 268.2).

Under the LDR regulatory framework, the disposal of RCRA hazardous wastes in or on the land is prohibited (after specified effective dates) unless the waste has been treated to meet applicable treatment standards; or it has been demonstrated to a reasonable degree of certainty, that there will be no migration of hazardous constituents from the disposal unit or injection zone for as long as the wastes remain hazardous (i.e., a "no migration" petition). Treatment standards are based upon the performance of the Best Demonstrated Available Technologv (BDAT). These standards are established either as constituent concentration levels (in the waste or a waste extract) that reflect the performance of BDAT, or as specific treatment technologies.

A treatment standard for LDRs can be expressed as:

$\sqcup$ Concentration Levels - constituent concentration levels that must be achieved before the wastes or treatment residual can be land disposed. Any treatment technology (i.e., not just the BDAT) may be used, as long as hazardous constituents in the waste are treated to the specified concentration levels. 
Treatment Technologies - the standard specifies which technology must be used to treat the waste before land disposal.

Deactivation - this treatment standard requires the removal of hazardous characteristics of waste due to its ignitability, corrosivity and/or reactivity.

Note: EPA's efforts to develop LDR treatment standards applicable to newly listed and identified wastes are addressed in a suit filed by the Environmental Defense Fund against EPA (March 1989). Deadlines for establishing treatment standards for these new hazardous wastes have been identified in a proposed consent decree.

\section{Key LDR Rulemakings}

A series of five LDR rulemakings were mandated by Congress under HSWA. At specified statutory deadlines, further land disposal of particular categories of hazardous wastes was to be prohibited if EPA had not set treatment standards, provided an extension to the LDR effective date (based on the lack of available treatment, recovery or disposal capacity), or granted a no-migration petition. As of June 1990, EPA had promulgated standards for each of the five statutorily-designated categories of hazardous wastes. Below are the five corresponding LDR rulemakings:

The Solvent - Dioxin Rule was effective on November 8, 1986. The framework for implementing the land disposal restrictions program was established in this final rule. The rule also included specific treatment standards and effertive dates for the first category of wastes subject to the restrictions, F001-F005 spent solvent wastes, and F020-F023 and F026-F028 dioxin-containing wastes. 
- The California List Rule was effective on July 8, 1987. The waste groups covered in this regulation include liquid and non-liquid Halogenated Organic Compounds (HOCs); liquid hazardous wastes containing polychlorinated biphenyls (PCBs); the toxic metals arsenic, chromium VI, mercury, selenium, cadmium, nickel, and thallium; free cyanides; and corrosive liquid hazardous waste (having a $\mathrm{pH} \leq 2.0$ ). All of these waste groups (except for the corrosive waste category) must exceed specified constituent concentration levels to be considered a California list waste. Dilute HOC wastewaters, toxic metals, free cyanides, and corrosive liquids must be treated to the statutory prohibition levels or made non-liquid before land disposal.

The First Third Rule was effective on August 8, 1988. This rule covers 183 hazardous wastes. It prohibited the land disposal of 62 wastes and set restrictions on 121 others. It regulates some of the F-coded wastes such as wastewater treatment sludges from certain electroplating processes; some of the K-coded wastes such as acetonitrile production wastes; and some of the P- and U-coded wastes which are discarded commercial chemical products and off-specification forms of chemicals such as formaldehyde.

The Second Third Rule was effective on June 8, 1989. Treatment standards for 67 additional wastes and for the F-coded wastes not addressed in the First-Third are established in this rulemaking. This rule sets treatment standards for many Second Third wastes, some First Third wastes subject to "soft hammer" provisions, and certain Third Third wastes.

Note: In the First Third and Second Third rules, EPA moved radioactive mixed wastes containing First and Second Third waste components to the Third Third. 
The Third Third Rule was effective on May 8, 1990. This fifth major LDR rulemaking sets iieatment standards and imposes restrictions on 344 listed wastes, five newly listed wastes, and the characteristic hazardous wastes (except for the newly identified TC wastes). This rule also established treatment standards specific to certain radioactive mixed waste and multi-source leachate, as well as alternative standards for lab packs. Two-thirds of the listed wastes have treatment standards expressed as concentrations in the treated wastes, while the remaining wastes have treatment standards expressed as specific technologies.

Note: A sixth major LDR final rule was published on August 18, 1992 (57 FR 37194), which covers certain newly listed wastes and hazardous debris.

\section{Radioactive Mixed Waste}

Radioactive mixed waste (RMW) contains both radioactive and hazardous constituents. The hazardous component of these wastes are subject to regulation under RCRA, and the radioactive component is regulated by the Atomic Energy Act (AEA). Since RCRA requirements apply to the hazardous portion, these wastes are subject to the land disposal restrictions.

Separate treatability groups were established for four specific types of RMW in the Third Third LDR final rule. These groups were separated on the basis that such wastes could not be treated using the BDAT for the corresponding non-hazardous wastes. The existing LDR treatment standards promulgated for non-radioactive hazardous wastes apply to the hazardous component of most RMW, except for wastes that fall into one of the four specific RMW categories discussed below:

[ Vitrification is the specified technology for the high-level waste fraction generated during the reprocessing of fuel rods. For certain remaining low-level radioactive process waste 
fractions, EPA indicates that it is possible to achieve the promulgated treatment standards with intended treatment processes (e.g., grout stabilization of low-level radioactive supernate solution/salts, incineration of low-level radioactive organic waste containing benzene).

Macroencapsulation is the specified treatment for radioactive lead solids (i.e., RMW containing elemental lead). This separate subcategory does not include lead containing treatment residuals such as hydroxide sludges, other wastewater treatment residuals or, certain organo-lead materials and incinerator ashes.

Amalgamation is the treatment standard for RMW containing elemental mercury. This standard may be achieved by utilizing various inorganic reagents that are effective in forming mercury amalgamations (including gold).

口 "IMERC" is the treatment standard for mercury-containing hydraulic oil contaminated with radioactive materials. This technology code represents the incineration of wastes containing organics and mercury in units operated in accordance with the technical operating requirements of 40 CFR Part 264, Subpart O, and 40 CFR Part 265, Subpart O, with residues complying with the corresponding treatment standard.

In the Third Third LDR final rule it was determined that insufficient treatment capacity existed for RMW containing First, Second and Third Third hazardous waste components. As a result EPA granted a two year national capacity variance for these wastes extending the effective date until May 8, 1992 (55 $F R$ 22644). EPA also granted a two-year national capacity variance for soil and debris contaminated with RMW, which expired on May 8, 1992. Since this variance expired, EPA has approved case-by-case variances for certain hazardous soil and debris wastes on a national basis. 
Keep in mind that hazardous wastes that are subject to a national capacity variance must still comply with California list prohibitions, where applicable (i.e., if the wastes contain any California list constituents). It should be noted that RMW containing spent solvent, dioxin, and California list wastes were not granted a capacity variance and the treatment standards corresponding to these wastes are currently effective.

\section{LDR Storage Prohibition}

Under the LDR regulations, storage of prohibited wastes by generators or Treatment, Storage and Disposal Facilities (TSDFs) is itself prohibited except where storage is "solely for the purpose of accumulating sufficient quantities of waste to facilitate proper treatment, recovery or disposal." TSDFs may store restricted hazardous wastes as long as necessary, provided that such storage is in accordance with the statutory provision. However, if a TSDF stores a restricted waste for more than one year, it bears the burden of proof that storage was solely for this purpose. For storage of less than one year, EPA bears the burden of proof.

An exception to this requirement applies to liquid hazardous waste containing PCBs at concentrations greater than or equal to $50 \mathrm{ppm}$. These wastes cannot be stored for more than one year in accordance with 40 CFR 761.65(b), i.e., implementing regulations under the Toxic Substances Control Act (TSCA) regarding storage for disposal requirements.

Under the LDR storage prohibition, tanks and containers that are used for storing restricted wastes must be clearly marked with a description identifying the contents (e.g., "Hazardous Waste"), and with the date on which accumulation of waste in the tank or container began. Wastes that are placed in storage prior to the LDR effective date applicable to that waste are not subject to the LDR prohibitions on storage. Once taken out of 
storage, however, these wastes must meet the applicable treatment standards prior to land disposal (RCRA Information Brief "Waste Management and the LDR Storage Prohibition" EH231-011/0592).

\section{Variances, Extensions, and Exemptions}

The LDR regulations provide certain compliance alternatives that delay the effective date of prohibitions or allow a variance from the prohibitions. Under certain conditions, EPA may grant a variance from the treatment standard, an extension to the LDR effective date based on capacity determinations, or an exemption from the prohibition for a specific waste at a specific site. EPA has established six types of variances, extensions and exemptions:

口 National Capacity Variance (40 CFR 268.30 - 268.35). A national capacity variance is provided when EPA determines that sufficient treatment capacity for specific RCRA hazardous waste codes is not available on a nationwide basis. The variance extends the LDR effective date of the waste until the earliest date treatment capacity becomes available, but by law this variance can not be longer than two years. When the LDR effective date for a waste is extended, the new effective date is listed in Appendix VII of 40 CFR Part 268. During the period of a national capacity variance, you may continue to land dispose the waste without treatment. If wastes that are granted such a capacity variance are to be placed in a landfill or surface impoundment, then such disposal may only be in a unit meeting the minimum technological requirements of RCRA (i.e., double liner, leachate collection system, and ground water monitoring).

Note: A two year national capacity variance was granted for RMW containing First, Second, and Third Third Wastes, which expired May 8, 1992. 
Case-by-Case Extension (40 CFR 268.5). A case-by-case extension may be granted if the petitioner can demonstrate a binding contractual commitment exists to provide alternate treatment for the waste, but through no fault of their own, the petitioner cannot bring this new capacity on-line by the effective date of the LDR treatment standards. EPA may grant a case-by-case extension of up to one year, renewable only once, for a total of two years.

Note: In November 1991, DOE submitted an application to EPA requesting a case-by-case extension for certain mixed wastes subject to the Third Third LDR rule. On May 26, 1992 ( 57 FR 22024), EPA published a notice of proposed decision to grant a one-year extension for mixed wastes addressed in the DOE case-by-case petition. In addition, EPA published a notice approving a generic case-by-case capacity variance for many types of hazardous debris [May 15, 1992, Hazardous Debris Case-by-Case Capacity Variance (57 FR 20766) and October 20, 1992, Interim Final Hazardous Soil Caseby-Case Capacity Variance (57 FR 47772)].

- Treatability Variance (40 CFR 268.44). Generators whose wastes cannot be treated to the established treatment standards may petition EPA for a treatability variance. For EPA to grant a variance, the petitioner must successfully demonstrate that the waste differs significantly from the wastes evaluated by EPA in developing the treatment standards. The petitioner must also demonstrate that the waste cannot be treated to the level or by the method specified as the treatment standard, or that the existing level or method is inappropriate for the waste. In granting a variance, EPA will establish a new treatability group for that waste, and set a new treatment standard.

Equivalent Method Variance [40 CFR 268.42(b)]. If EPA has specified a method of treatment as the treatment standard 
for a waste, a generator or facility may submit an application to the EPA Administrator demonstrating that an alternative treatment method can achieve performance equivalent to that of the method specified as the treatment standard. If approved, wastes treated by this alternative treatment method comply with the treatment standard and thus can be land disposed.

No-Migration Petition (40 CFR 268.6). EPA will consider allowing land disposal of restricted wastes if a petitioner can demonstrate, to a reasonable degree of certainty, that such disposal will not allow migration of hazardous constituents from the disposal unit or injection zone for as long as the wastes remain hazardous. A successful no-migration petition will allow land disposal of specific restricted wastes at a specific site.

- Treatment in Surface Impoundment Exemption (40 CFR 268.4). Owners and operators of surface impoundments seeking an exemption for treatment of restricted wastes must certify to the EPA Regional Administrator that the impoundment meets minimum technological requirements (MTRs) and must submit a copy of the facility's revised waste analysis plan that outlines methods for representative sampling and proper testing, frequency of removal, and methods for removal of restricted residuals.

Note: Treatment residuals not meeting the LDR treatment standards must be removed at least once every 12 months, and the principal method of treatment must not be evaporation. MTRs require that any new landfill or surface impoundment (or expansions to the existing units) be outfitted with 2 or more liners, a leachate collection system and groundwater monitoring wells. 


\section{Restricted Waste vs. Prohibited Waste}

Restricted wastes are those categories of hazardous wastes that are prohibited from land disposal, either by regulation or by statute (i.e., a hazardous waste is considered restricted following an applicable statutory deadline); wastes constitute "restricted" wastes regardless of whether or not subcategories of such wastes are subject to a case-by-casc extension, no-migration exemption, or national capacity variance, any of which would make the waste eligible for land disposai. In other words, if you have a restricted waste, your particular wasis is not necessarily prohibited from land disposal, for example, if you have an exemption, extension, or variance. Prohibited wastes, on the other hard, are restricted wastes that are currently ineligible for land disposal (i.e., a subset of restricted wastes).

\section{Measuring Compliance with the LDR Treatment Standards}

Compliance with the LDR treatment standards must be demonstrated using the following methods, as appropriate:

J Total Waste Anci'vsis - Measurement of the total concentration levels of the hazardous constituents in the waste or treatment residuals. This analytical procedure applies to LDR treatment standards for wastes listed in 40 CFR 268.43, Table CCW.

」 Toxicity Characteristic Leaching Procedure (TCLP) For most of the LDR "reatment standards based on constituent concentrations in waste extract (i.e., 40 CFR 268.41, Table CCWE), EPA requires that an extract of the waste be developed and tested using the TCLP to determine whether the waste requires treatment. Additionally, the TCLP is used to determine whether a waste exhibits the hazardous characteristic of toxicity, and serves as a monitoring technique to 
determine whether a treated waste meets the applicable waste treatment standard.

- EP Toxicity Test - The TCLP analytical method must be used to measure compliance with the treatment standards expressed as concentrations in waste extract (i.e., 40 CFR 268.41, Table CCWE) with the exception of a few specified wastes. For these particular wastes (e.g., certain arsenic or lead non-waste waters), either the TCLP or the EP toxicity test must be used to determine whether the constituent level has been met.

$\checkmark$ Paint Filter Liquids Test (PFLT) - The California list rule requires that the PFLT be used to determine whether a waste is considered to be a liquid. This method consists of placing a predetermined amount of a waste on a paint filter and if any portion of the waste passes through the filter in five minutes, the waste is deemed to contain free liquids. According to EPA once a waste is determined to be a liquid, the entire waste is prohibited, not just the liquid portion.

\section{Testing, Recordkeeping, Notification, and Certification of Compliance}

Once it is determined that a waste is restricted under the LDRs, treatment facilities or disposal facilities must test the waste at a frequency specified in the facility's waste analysis plan to demonstrate compliance with LDR treatment standards or California list prohibition levels prior to land disposal.

Records must be maintained of notices, certifications, demonstrations and waste analysis. For generators, these records must be retained for at least five years (this retention period, however, is automatically extended during an enforcement action). TSDFs must maintain required information in their operating records until the facility closes. 
All restricted wastes that are shipped to an off-site treatment, storage, or disposal facility must be accompanied by a notification that includes the EPA hazardous waste number and the applicable LDR restriction that is in effect for those wastes.

There must be certification that LDR treatment standards have been attained before the waste is land disposed. If the waste meets the applicable standards without treatment, this certification must be supplied by any person who generates, treats, stores or disposes of hazardous wastes. The information referenced by the certification must be true, accurate, and complete and there are significant penalties for submitting false information, including fine and imprisonment.

Note: All restricted wastes, whether treated and disposed on-site or sent off-site to a TSDF, are subject to the testing and recordkeeping requirements which include notification and certification requirements.

\section{Acronyms}

$\boldsymbol{A E A} \quad$ Atomic Energy Act of 1954

BDAT Best Demonstrated Available Technology

CFR Code of Federal Regulations

$D O E \quad$ Department of Energy

$\boldsymbol{E P}$ Extraction Procedure

$\boldsymbol{E P A}$ Environmental Protection Agency

FR Federal Register

HOCs Halogenated Organic Compounds

HSWA Hazardous and Solid Waste Amendments of 1984 
INCIN Incineration

LDRs Land Disposal Restrictions

MTRs Minimum Technology Requirements

PCBs Polychlorinated Biphenyls

$\boldsymbol{R C R A}$ Resource Conservation and Recovery Act of 1976

$\boldsymbol{R} \boldsymbol{M} \boldsymbol{W}$ Radioactive Mixed Waste

TC Toxicity Characteristic

TSCA Toxic Substances Control Act

TSDFs Treatment, Storage and Disposal Facilities

TCLP Toxicity Characteristic Leaching Procedure

\section{Glossary Of Terms}

Atomic Energy Act (AEA): The AEA, enacted in 1954, outlines roles and responsibilities for the control of nuclear energy. The AEA's primary objective is to assure proper management of nuclear materials. The Department of Energy (DOE) has authority to manage and regulate all the materials generated at its facilities. The Nuclear Regulatory Commission (NRC) regulates these materials when generated or managed by private or commercial organizations.

Code of Federal Regulations (CFR): All Federal regulations in force are published annually in codified form in the Code of Federal Regulations.

Corrosivity: A characteristic of hazardous waste under RCRA in which a waste exhibits a $\mathrm{pH} \leq 2.0$ or $\geq 12.5$, or is capable of corroding steel at a rate of more than 0.25 inches per year. 
Extraction Procedure Toxicity Test (EP Tox Test): Under the RCRA hazardous waste management program, a characteristic of hazardous waste was developed to identify wastes likely to leach hazardous concentrations of particular toxic constituents into the groundwater. The EP Tox Test was designed to represent this hazardous waste characteristic. Using this procedure, the extract was analyzed to determine whether the concentration of a specified contaminant was above designated regulatory thresholds. With respect to the RCRA toxicity characteristic this test was replaced (March 29, 1990, Final Rule) by the Toxicity Characteristic Leaching Procedure (TCLP). However, the EP Tox Test may still be used to measure compliance with LDR treatment standards for a few specified wastes.

Facility: All contiguous land, and structures, other appurtenances, and improvements on the land, used for treating, storing, or disposing of hazardous waste. A facility may consist of several treatment, storage, or disposal operational units (e.g., one or more landfills, surface impoundments, or combinations of them).

Federal Register (FR): Each Federal working day, the Government Printing Office publishes current Presidential proclamations and Executive Orders, Federal agency regulations having general applicability and legal effect, proposed agency rules, and documents that are required by statute to be published in the Federal Register.

Hazardous and Solid Waste Amendments (HSWA): Amendments to RCRA enacted in 1984, that minimize the nations reliance on land disposal of hazardous waste by, among other things, requiring EPA to evaluate all listed and characteristic hazardous wastes according to a strict schedule to determine which wastes should be restricted from land disposal. 
Hazardous Waste: As defined in RCRA, a solid waste or combination of solid wastes, which because of its quantity, concentration, or physical, chemical, or infectious characteristics may cause, or significantly contribute to an increase in mortality or an increase in serious irreversible, or incapacitating reversible, illness, or pose a substantial present or potential hazard to human health or the environment when improperly treated, stored, transported, or disposed of, or cinerwise managed.

Ignitability: A characteristic of hazardous waste under RCRA in which liquid waste has a flash point lower than $140^{\circ}$ $\mathrm{F}$, or is a physically solid waste capable of causing fire.

Incineration: Burning of certain types of solid, liquid, or gaseous materials under controlled conditions to destroy hazardous waste.

Land Disposal Restrictions: This RCRA regulatory program prohibits the land disposal of hazardous wastes into or on the land unless EPA finds that it will no longer endanger human health and the environment. HSWA requires EPA to develop levels or inethods of treatment that substantially diminish the toxicity of the waste or the likelihood that hazardous constituents will migrate from the waste that must be met before prohibited wastes are land disposed. Strict statutory deadlines were imposed on EPA to regulate the land disposal of specific hazardous wastes, concentrating first on the most harmful. EPA has met all the Congressionally mandated dates.

Prohibition Levels: Concentration-based treatment standards that when exceeded trigger statutory and regulatory land disposal prohibitions on certain wastes. This term is also used to refer to the constituent concentration levels established by the California List Rule that Congress incorporated into the 1984 Amendments to RCRA. 
Reactivity: A characteristic of hazardous waste under RCRA reflecting waste that is explosive, reacts violently with water, generates toxic gases when exposed to water or liquids that are moderately acidic or alkaline, or exhibits other reactive properties as specified in the RCRA regulations.

Resource Conservation and Recovery Act (RCRA): The Resource Conservation and Recovery Act of 1976 is a Federal law that established a structure to track and regulate hazardous wastes from time of generation to disposal. The law requires safe and secure procedures to be used in treating, transporting, storing and disposing of hazardous substances. RCRA is designed to prevent new, uncontrolled hazardous waste sites. The law also regulates the disposal of solid waste that may not be considered hazardous. The Act was amended on November 8 , 1984. The 1984 amendments called HSWA significantly expanded the scope and requirements of RCRA.

Subtitle C Program: The hazardous waste management system under RCRA. This program consists of requirements intended to systematically control the collection, source separation, storage, transportation, processing, treatment, recovery and disposal of hazardous wastes.

Subtitle D Facility: The nonhazardous waste management system under RCRA. This program covers a broad range of materials, including industrial wastes, mining and other largevolume wastes, household wastes and other municipal garbage, and ash from the combustion of municipal wastes.

Toxicity Characteristic Leaching Procedure (TCLP): The EPA issued a final toxicity characteristic (TC) rule on March 29,1990 . The final rule establishes the Toxicity Test (EP Tox) (45 FR 33084) and an update to the existing TCLP, which was promulgated under the Land Disposal Restrictions (LDR) regulations (51 FR 40572). 'This rule also adds 25 organic chemicals 
to the existing list of 14 regulated toxicity characteristic waste constituents.

Treatment, Storage and Disposal Facilities (TSDF): Any building, structure, or installation where hazardous wastes have been treated, stored or disposed. TSD facilities are regulated by EPA and authorized states under RCRA.

\section{References}

$\square$ Environmental Guidance Program Reference Book: Resource Conservation and Recovery Act (ORNL/M-1897, Rev. 11, March 15, 1992);

0 "Land Disposal Restrictions for Third Third Scheduled Wastes, Final Rule," June 1, 1990, 55 FR 22520;

¿ EH-231 Memorandum, July 9, 1990, "Final Rule Regarding I and Disposal Restrictions for Third Third Scheduled Wastes;"

EPA Question and Answer Document entitled "Implementing the Land Disposal Restrictions" November 1989;

] "Managing Waste to Meet Federal Land Ban Rules," Pollution Engineering, October 1990, J. Biedry;

$\checkmark$ EH-23l Guidance Document, Complying with the Notification and Certification Requirements of the RCRA Land Disposal Restrictions, January 1989;

$\checkmark$ EH-23I RCRA Guidance Manual, May 1990, Obtaining Variances from the Treatment Standards of the RCRA Land Disposal Restrictions;

$\square$ Joint DOE/EPA publication, October 18, 1991, Compendium of CERCLA ARARs Fact Sheets and Directives (Compilation of Superfund LDR Guidance and LDR-Related Directives); 
๑ EH-23I Memorandum, November 29, 1989, "RCRA Land Disposal Restrictions (LDR) Summary Booklet;"

- Glossary of CERCLA Related Terms and Acronyms (DOE/EH-0219, October 1991);

口 "Land Disposal Restrictions for Newly Listed Wastes and Hazardous Debris, Final Rule," August 18, 1992, 57 FR 37194;

- EH-231 RCRA Information Brief, "Waste Management and the Land Disposal Restriction Storage Prohibition" (EH231-011/0592, May 1992);

口 "Hazardous Waste Management System: Land Disposal Restrictions, Notice to Approve Hazardous Debris Case-EyCase Capacity Variance," May 15, 1992, 57 FR 20766;

口 "Hazardous Waste Management System: Land Disposal Restrictions (LDR); DOE Mixed Wastes Extension Application, Notice of Proposed Decision on Request for an Extension of the LDR Effective Date for Certain Mixed Wastes," May 26, 1992, 57 FR 22024; and

口 "Hazardous Waste Management System: Land Disposal Restrictions, Approval of Interim Final Hazardous Soil Case-By-Case Capacity Variance," October 20, 1992, 57 FR 47772. 

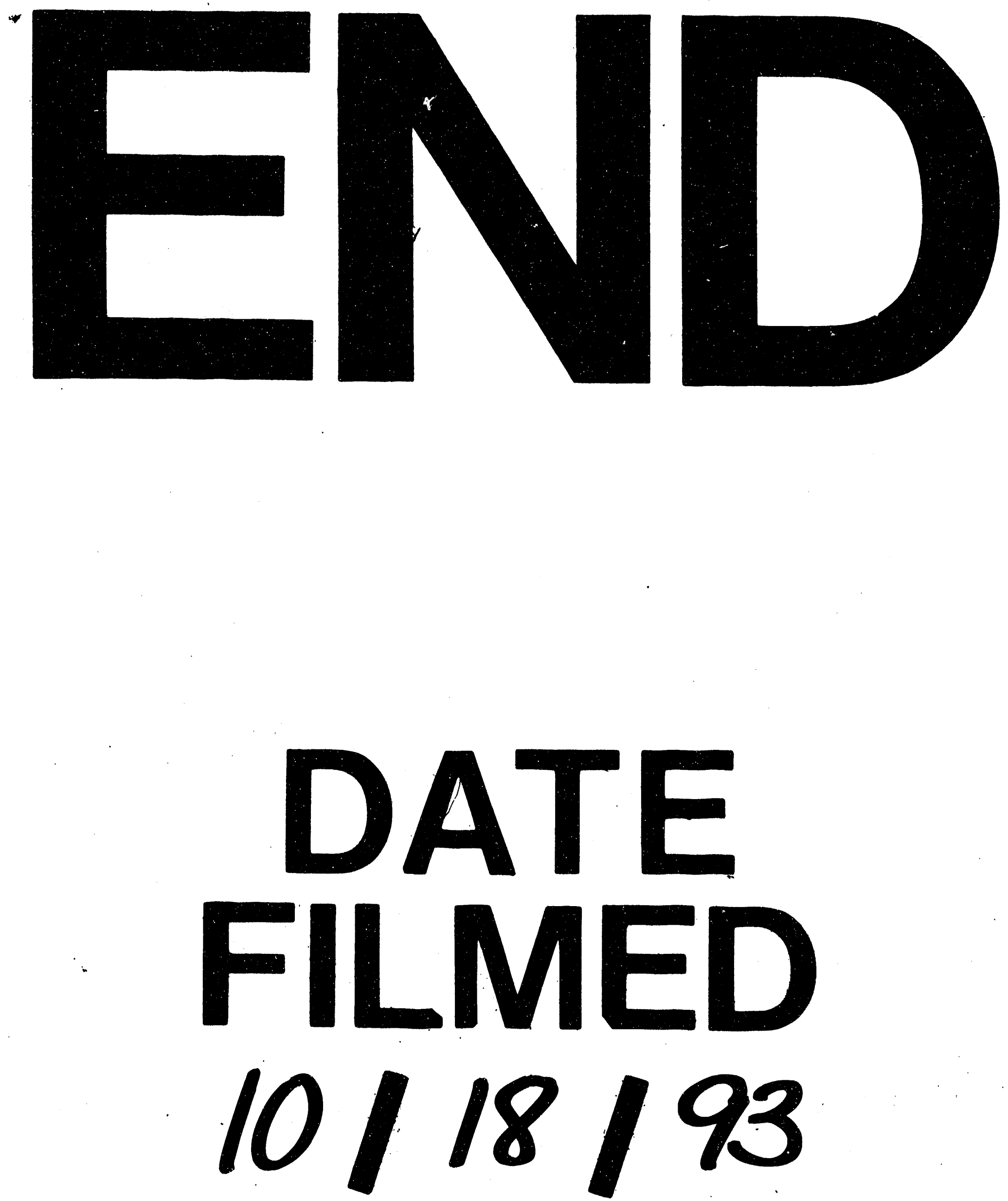
